\title{
Paper
}

\section{Optimization of Resin Molding Process by Functional Evaluation Method Focusing on Melting Energy Related to Resin Filling Characteristics}

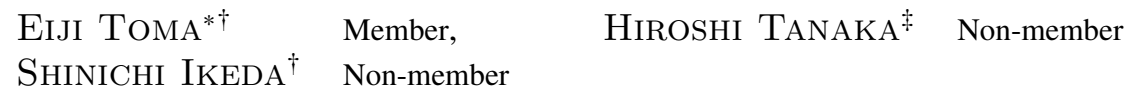

(Received August 14, 2020, revised October 19, 2020)

\begin{abstract}
In recent years, along with the increasing demand for plastic products and the deepening of academics, mass production, weight reduction, and higher precision are progressing. In the field of design development and production technology, there is an increasing need for analysis technology related to resin flow and behavior in order to solve problems related to quality assurance such as molding defects and product strength. Especially in the resin molding process, it is an important issue to create a quality function that applies the analysis of complex multidimensional information because of the high degree of freedom in product shape and mold structure. In order to solve the quality issues regarding the strength and dimensional stability of resin materials, it is effective to apply the "Functionality Evaluation Method" in robust design which is an analytical evaluation method. In this study, we focus on the function of managing the resin filling density in the mold (the input/output relationship of the melting energy related to the resin filling characteristics) for the optimization of resin strength and dimensional stability. We propose a functional evaluation method with the ideal function of stabilizing the resin filling density based on the original definition of material mechanics. As a result of verification of the proposed method, it was clarified that it is extremely important to make the resin filling density in the mold uniform to stabilize the strength of the resin injection molded product.
\end{abstract}

Keywords: Resin Molding Process, Resin Filling Characteristics, Robust Design, Functional Evaluation Method, Energetic S/N ratio,

\section{Introduction}

In recent years, the automobile industry has been actively promoting environmental measures even more than ever before, and as a part of this activity, the improvement of fuel efficiency by reducing the weight of parts is being promoted. As an example of this, resin-made steel pulleys for automobiles are being actively used. European automobile manufacturers are promoting the use of resin for pulleys for power steering and idler pulleys. In particular, the plasticization rate of the transmission pulley used in drive transmission parts around the engine has reached about 30\% (Fig. 1). However, Japanese automobile manufacturers have a low plasticization rate of pulleys of 5 to $6 \%$, and future growth is expected. Plasticization is the replacement of steel parts with resin, the purpose of which is to reduce weight and reduce costs. The resin pulleys currently in practical use cannot be said to have sufficient characteristics as substitutes for steel pulleys in terms of strength and dimensional stability [1] [3].

\footnotetext{
* Corresponding: toma-e @ tomakomai-ct.ac.jp

† National Institute of Technology, Tomakomai College

443, Tomakomai, Nishikioka, Hokkaido, 059-1275 Japan

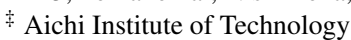

1247, Yachikusa, Yakusa, Toyota, Aichi, 470-0392 Japan
}

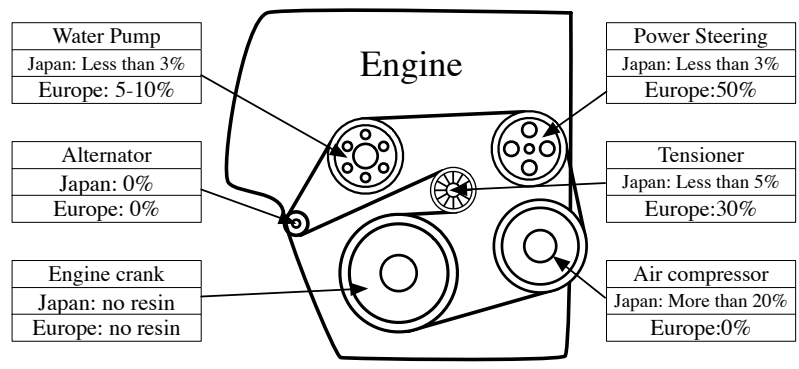

Figure 1: Plasticization rate of parts around automobile.

In the engineering process, products whose quality has been stabilized to the limit of theoretical values are easily affected by variations in conditions. As a result, the tradeoff of "increasing defect rate and decreasing process capability" develops [4] [5].

In this paper, we apply a functional evaluation method with the ideal function of stabilizing the resin filling density in the mold. It is clarified that homogenizing the resin filling density in the mold is extremely important for optimizing the resin pulley strength. 

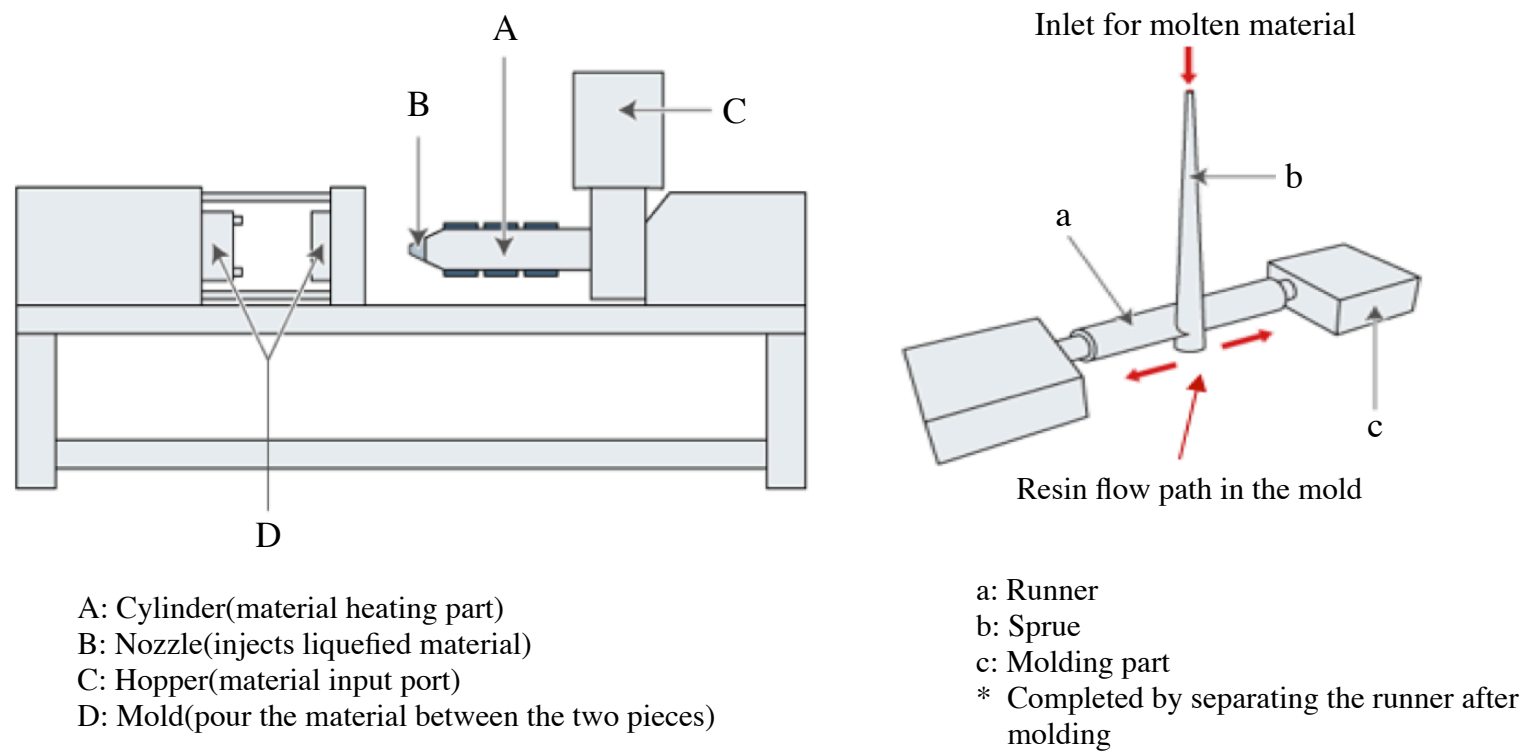

A: Cylinder(material heating part)

B: Nozzle(injects liquefied material)

C: Hopper(material input port)

D: Mold(pour the material between the two pieces) molding

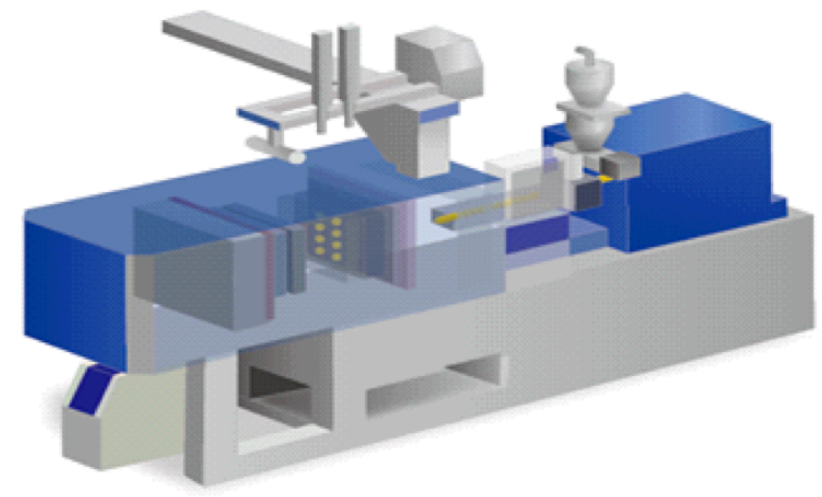

Figure 2: Main structure and model of injection molding machine.

\section{Overview of resin injection molding process}

There are several types of resin molding methods depending on the purpose, but in this research, we approach the optimization of the injection molding method suitable for the mass production method of resin pulleys. The injection molding method is a method of obtaining a molded product by injecting a heated and melted material into a mold, cooling and solidifying the material. It is suitable for mass production of products with complicated shapes and is a major field of molding processing.

Injection molding is one of the molding methods using a mold. This is a processing method that heats and melts a material such as synthetic resin (plastic), sends it to a mold, and then cools it to form the desired part.

Figure 2 shows the main structure and model of the injection molding machine. As shown in Fig. 3 the injection molding process is roughly divided into 6 steps: (1) mold clamping, (2) injection, (3) pressure retention, (4) cooling, (5) mold opening, and (6) product removal. Specifically, first, pelletized resin is put into a hopper which is a material feeding port. The pellets are warmed in the cylinder and become liquid, ready for injection. The material sent out from the nozzle of the injection section passes through a pipe line called a sprue in the mold, and further flows into a mold- ing section through a branched runner. After the material has cooled and solidified, the mold opens and the molded product is discharged to the outside. Through this process, continuous production becomes possible [6] [9].

The injection molding machine is divided into a mold clamping unit and an injection unit. The mold clamping unit has a mold opening/closing function and uses a toggle type. The injection unit heats and melts the resin and injects it into the mold. Rotate the screw to collect the resin charged from the hopper at the front of the screw and then inject it.

The injection speed of the screw is controlled when the resin is flowing, and the pressure is controlled after the resin is filled. The switching from speed control to pressure control is set to switch when a certain screw position or injection pressure is reached [10] [12].

In practice, it is often the case that a plurality of molded products are manufactured at the same time by a single injection molding, so it is important that the molten material uniformly flows into all parts. Therefore, it is necessary to devise the shape of the mold such that the runners have the same length for designing.

Injection molding is a processing technique suitable for mass production. However, in order to produce a highly 


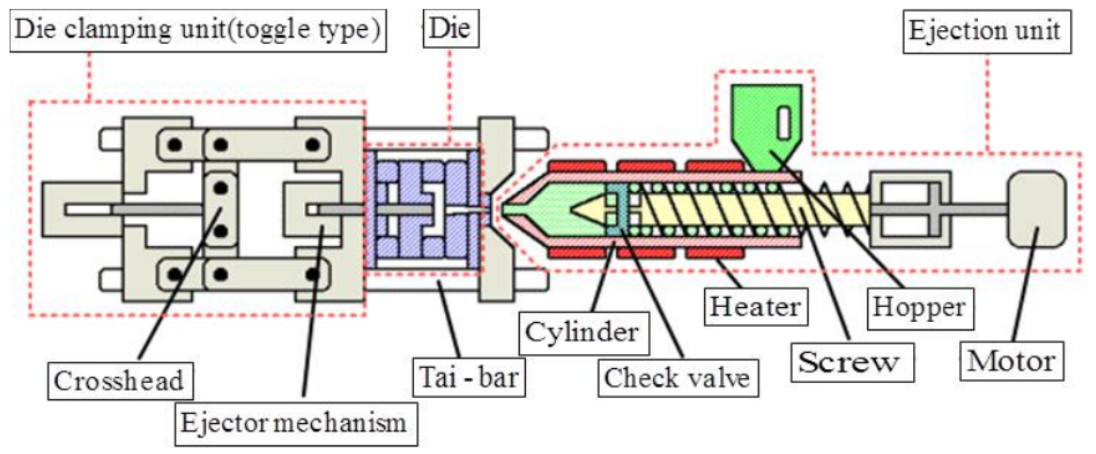

Figure 3: Injection molding.

accurate molded product, it is necessary to extract various processing parameter conditions such as resin material selection accuracy, mold processing accuracy, and temperature and speed at which the material is injected.

\section{Analysis of resin filling characteristics by "Func- tional Evaluation Method"}

In this chapter, we apply the functional evaluation method of parameter design which is the core method of "Robust design" to approach the stabilization of the resin filling density focusing on the input/output relationship of the melting energy.

3.1 Overview of Robust design Figure 4 shows the concept of robust design in quality engineering. The concept of improving technology to bring it closer to what it should be is called robust design. Robust means stability in quality engineering. Parameter design is one of the central methods of robust design, and is a method for evaluating functionality and determining system parameter values.

Parameters are design constants and components of the system and are selected as control factors in parameter design experiments. In the combination of system parameters, robustness is improved by deliberately generating variations by noise factors and optimizing the level of strong control factors that can counter the variations [13] [14].

In parameter design, it is important to understand the target function of the system. The objective function refers to the role that the system should play, and the quality characteristics are divided into the following four types. By taking up the objective function, the design information can be utilized in other similar systems, and the versatility of the technology is expanded [15] [16].

(a) Preferably small characteristics (nonnegative and smaller the better)

(b) Preferably large characteristics (nonnegative and larger the better)

(c) Preferably target characteristics (with target value)

(d) Dynamic characteristics (I/O correlation, output stability)

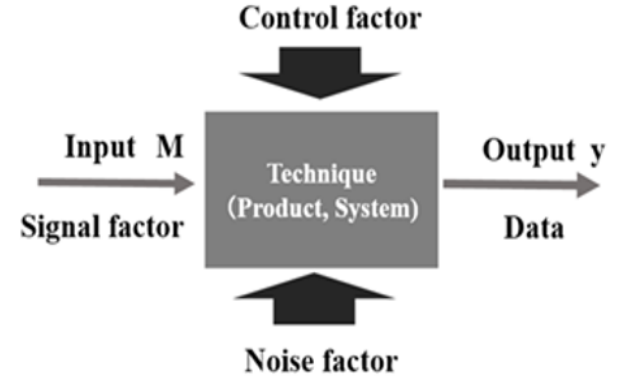

Figure 4: Robust design.

The purpose of this research is to stabilize the filling density of output against the processing conditions of input in injection molding.

The evaluation procedure for robust design is shown in Fig. 5. In robust design, start by clarifying the functions of the system. We define it as an ideal function of the input (signal factor) and output (characteristic value) of the system. In order to realize the ideal function, the experiment is performed efficiently using the orthogonal table, and the effect of each control factor is grasped by the SN ratio, sensitivity, and slope $\beta$. After that, the optimum conditions and comparison conditions are determined from the factoreffect diagram, and the average of each process is obtained to estimate the magnitude of improvement.

Finally, a confirmation experiment is performed to verify the reproducibility of the optimum condition gain.

3.2 Functional evaluation method and ideal function setting The ideal function of many system technologies is that the output changes linearly with respect to the input. The total output characteristic value (total work) of the system must be proportional to energy or work. Especially in the injection molding process, there are melting energy required to obtain resin strength and dimensional accuracy, and loss energy that affects productivity. In robust design, a "Functional evaluation method" that defines the functionality based on energy conversion and quickly evaluates its stability is important [17]. In this research, we focus on the fact that the ideal function that represents the input-output relationship has a linear relationship with energy conversion.

Figure 6 shows a cross-sectional view of the molded resin 


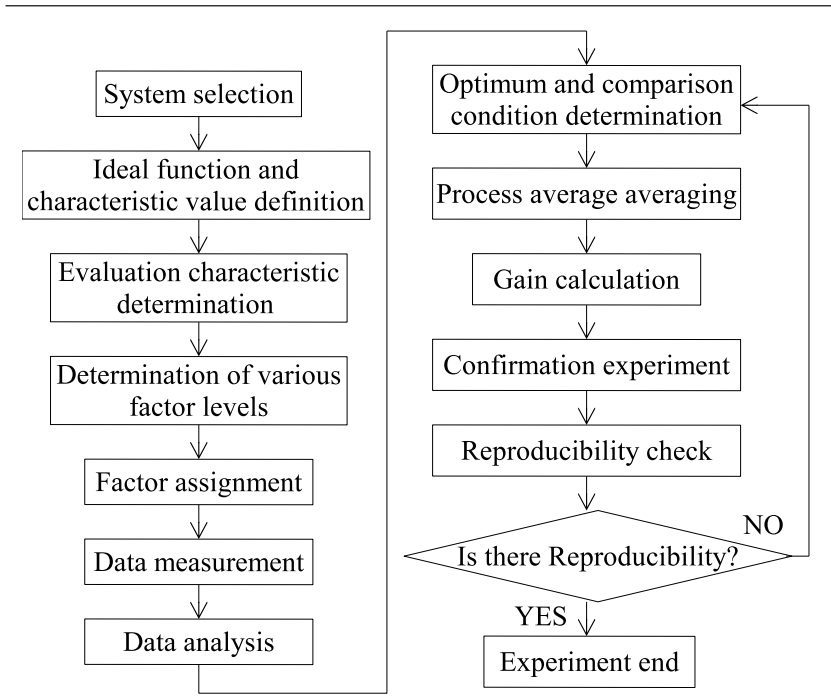

Figure 5: Robust design procedure.

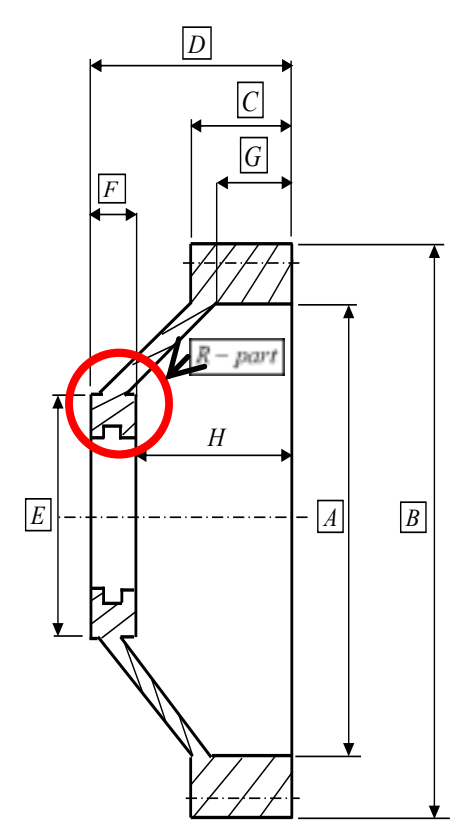

Figure 6: Pulley sectional view.

pulley component. The quality issue is that cracks occur in the $\mathrm{R}$ part indicated by the red circle due to insufficient mechanical strength and stress concentration. In this example, regarding the optimization of resin strength, the relational expression between the allowable stress of the resin material and the material density is newly defined as follows based on material mechanics considerations.

Allowable stress: $\sigma$

$$
\begin{array}{ll}
\sigma=M / Z=K \cdot \rho & \\
M: \text { Moment of force } & Z: \text { Section modulus } \\
K: \text { Proportional factor } & \rho: \text { Resin filling density }
\end{array}
$$

The physical quantity in Eq. 1 is regarded as constant for the dimension and shape [L] and the processing time [T], and is replaced with a unit of dimension.

Since the moment of force $M=\left[M L^{2} T^{-2}\right]$ and the section

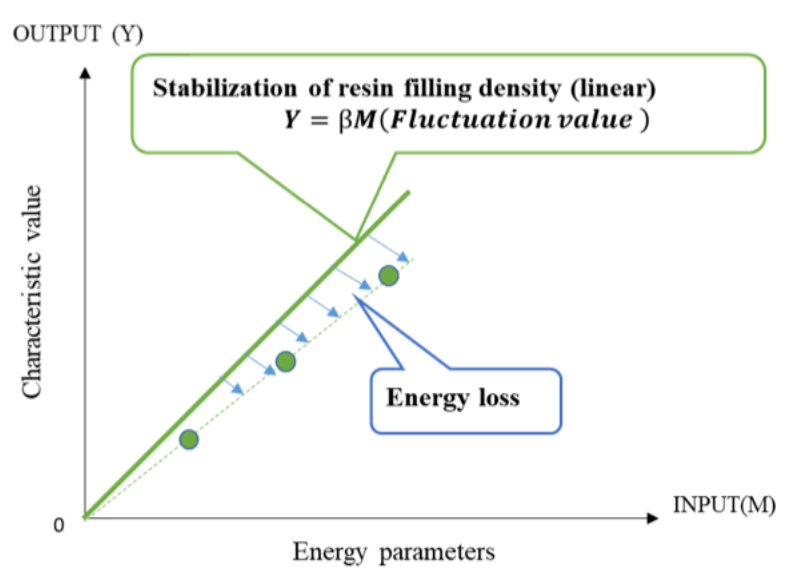

Figure 7: Relations of ideal function.

modulus $Z=\left[L^{3}\right]$, It can be defined as

$$
\sigma=\frac{\left[M L^{2} T^{-2}\right]}{\left[L^{3}\right]}=\left[L^{2} T^{-2}\right]\left[M L^{-3}\right]=K \cdot \rho .
$$

The allowable stress, which is an index of resin strength, is determined by the section modulus and the moment of force. Therefore, if the dimension and shape of the material and the processing time are constant, as shown in Eq. 1, the linear proportional (linear equation) to the allowable stress $\sigma$ and the material density $\rho$ with a proportional constant $K$. It can be defined as a relationship. Based on this definition, it can be estimated that stabilizing the degree of variation in the resin filling density $\rho$ is highly effective in optimizing the resin strength.

To optimize the resin strength, the ideal function shown in Fig. 7 is set from the function of controlling the resin filling density in the mold (input/output relationship of melting energy related to resin filling property) and the material mechanical definition. The main purpose of applying the "Functional evaluation method" is to extract parameter levels that make the fusion energy parameter and the stable function of the filling density closer to the ideal state and reduce variations and fluctuations. The difference from the ideal state can be considered as some kind of energy loss.

In other words, the function of injection molding is consumed other than the intended output, and as a result, the stability of the filling density is affected. The effectiveness of the ideal function, in which the input is used as the parameter (control factor) of the molding processing conditions related to the melting energy during resin flow and the resin filling density as the output is the characteristic value is verified [18].

3.3 Energetic $\mathrm{S} / \mathrm{N}$ ratio The conventional $\mathrm{SN}$ ratio, which is used in parameter design and represents the scale of variation, may change depending on the size (range) of the input signal and the number of data, and the technician should keep this in mind when acquiring data. There is a problem of having to analyze. The idea of the $\mathrm{SN}$ ratio is to evaluate the variation and non-linearity from the ideal functional state $(y=\beta M)$ by considering it as poor functional stability. 
Table 1: Data form.

\begin{tabular}{|c|c|c|c|c|c|c|}
\hline \multicolumn{2}{|c|}{} & \multicolumn{5}{|c|}{ Input signal M } \\
\cline { 3 - 7 } & $M_{1}$ & $M_{2}$ & $M_{3}$ & $\cdots$ & $M_{k}$ \\
\hline \multirow{2}{*}{$\begin{array}{c}\text { Noise } \\
\text { factor } \\
\mathrm{N}\end{array}$} & $N_{1}$ & $y_{11}$ & $y_{12}$ & $y_{13}$ & $\cdots$ & $y_{1 k}$ \\
\cline { 2 - 7 } & $N_{2}$ & $y_{21}$ & $y_{22}$ & $y_{23}$ & $\cdots$ & $y_{2 k}$ \\
\cline { 2 - 7 } & $\vdots$ & $\vdots$ & $\vdots$ & $\vdots$ & $\vdots$ & $\vdots$ \\
\cline { 2 - 7 } & $N_{n}$ & $y_{n 1}$ & $y_{n 2}$ & $y_{n 3}$ & $\cdots$ & $y_{n k}$ \\
\hline
\end{tabular}

The "Energetic S/N ratio" adopted in this study is a new SN ratio announced in June 2008 by a research member of the Kansai Quality Engineering Society which is a certified regional study group of the Quality Engineering Society [13]. Since all technologies involve the conversion and transfer of energy, an energy perspective is important in technological development and evaluation of their technical levels.

Energetic $\mathrm{S} / \mathrm{N}$ ratio is a technical quality evaluation measure (measurement) based on how various energies are used. Technical quality means that more energy input to the system can be stably used for the purpose (output) forever [21]. In the ideal functional state of injection molding, energy is decomposed into effective components $\left(S_{\beta}\right)$ and harmful components $\left(S_{N}\right)$, and the energetic $\mathrm{S} / \mathrm{N}$ ratio is calculated by the ratio of these. In the calculation of the energetic $S / N$ ratio, it can be expressed in decibel value as 10 times the common logarithm like the conventional type $\mathrm{SN}$ ratio.

The basic calculation formula of the energetic $\mathrm{S} / \mathrm{N}$ ratio $\left(\eta_{E}\right)$ is shown below. As shown in Table 1, it is assumed that the output noise $y_{i j}$ at the noise factor level $i(i=1,2, \cdots, n)$ and the signal factor level $j(j=1,2, \cdots, k)$ is obtained.

(a) Total variation component $S_{T}$

This is the sum of the squares of $n k$ pieces of data $y_{i j}$ and shows the variation from $y=0$.

$$
S_{T}=\sum_{i=1}^{n} \sum_{j=1}^{k} y_{i j}^{2}
$$

(b) Average slope size $\beta_{N 0}$

For some dynamic characteristics of the input signal, the slope of the noise factor $N_{i}$ level $\beta_{N i}$ is obtained by considering the effective component as the average slope.

$$
\beta_{N i}=\frac{\sum_{j=1}^{k} M_{J} y_{i j}}{\sum_{j=1}^{k} M_{j}^{2}}=\frac{L_{N i}}{r}
$$

Here,

$r$ : Effective divisor, $L_{N i}$ : Linear format

$$
\begin{gathered}
r \equiv \sum_{j=1}^{k} M_{j}^{2} \\
L_{N i} \equiv \sum_{j=1}^{k} M_{j} y_{j}
\end{gathered}
$$

The sum of squares of the signal, which is the denominator of $\beta$ in Eq. 3, is called the effective divisor $r$, and the sum of products of the numerator signal and output is called the linear form $L_{N i}$. From the slope $\beta_{N i}$ for each noise factor level, the average slope $\beta_{N 0}$ is given by the following equation.

$$
\beta_{N 0}=\frac{\sum_{i=1}^{n} \beta_{N i}}{n}
$$

(c) Average slope fluctuation (active ingredient) $S_{\beta}$

The variation of the average slope is expressed as the sum of squares of the size $y=\beta_{N 0} M$.

$$
\begin{aligned}
S_{\beta} & =n \sum_{j=1}^{k}\left(\beta_{N 0} M_{j}\right)^{2} \\
& =n \beta_{N 0}^{2} \sum_{j=1}^{k}\left(M_{j}\right)^{2}=n r \beta_{N 0}^{2}
\end{aligned}
$$

(d) Harmful component $S_{N}$

The harmful component represents the variation of the difference between each data and the proportional equation of the average slope, and is obtained by subtracting the effective component from the total variation component.

$$
S_{N}=\sum_{i=1}^{n} \sum_{j=1}^{k}\left(y_{i j}-\beta_{N 0} M_{j}\right)^{2}=S_{T}-S_{\beta}
$$

(e) Energetic $\mathrm{S} / \mathrm{N}$ ratio $\eta_{E}$

$$
\eta_{E}=10 \log \left(\frac{S_{\beta}}{S_{T}-S_{\beta}}\right)=10 \log \left(\frac{S_{\beta}}{S_{N}}\right)[\mathrm{db}]
$$

(f) Sensitivity $S_{E}$

The sensitivity when evaluating not only the energetic $\mathrm{S} / \mathrm{N}$ ratio but also the effective output magnitude is expressed in decibel values, where the square of the average slope magnitude $\beta_{N 0}$ is 10 times the common logarithm.

$$
S_{E}=10 \log \beta_{N 0}^{2}[\mathrm{db}]
$$

3.4 Level table and determination of various factors In this section, the optimization of the processing conditions is verified by "Dynamic characteristics evaluation (Energetic $\mathrm{S} / \mathrm{N}$ ratio)" with the objective function of stabilizing the fusion energy parameter and the filling density in injection molding. The dynamic characteristic is a characteristic that examines the output by changing the input, and is a method of evaluating the condition that minimizes the two-dimensional variation of the input and the output in the combination of various factors.

It is desirable that the input and output signals have a proportional relationship even under various usage conditions and environments, and more robust improvement effects can 
Table 2: Control factors.

\begin{tabular}{ccccc}
\hline Symbol & Control factors & Level 1 & Level 2 & Level 3 \\
\hline A & Gate width $(\mathrm{mm})$ & 0.5 & 0.8 & - \\
B & Mold temperature $\left({ }^{\circ} \mathrm{C}\right)$ & 165 & 175 & 185 \\
C & Resin temperature $\left({ }^{\circ} \mathrm{C}\right)$ & 96 & 102 & 108 \\
D & Measurement level $(\mathrm{mm})$ & 103 & 105 & 107 \\
E & Retention pressure $(\mathrm{Mpa})$ & 35 & 45 & 55 \\
F & Screw rotational speed $(\mathrm{rpm})$ & 490 & 510 & 530 \\
$\mathrm{G}$ & Bush temperature $\left({ }^{\circ} \mathrm{C}\right)$ & 165 & 185 & 205 \\
$\mathrm{H}$ & Virtual factor & $\mathrm{e} 1$ & $\mathrm{e} 2$ & $\mathrm{e} 3$ \\
\hline
\end{tabular}

Table 3: Noise factors.

\begin{tabular}{ccc}
\hline Noise factors & N1 & N2 \\
\hline Mold type & No.1Die & No.2Die \\
\hline
\end{tabular}

Table 4: Signal factors.

\begin{tabular}{cccc}
\hline Signal factors & M1 & M2 & M3 \\
\hline Injection pressure(Mpa) & 4.0 & 8.0 & 12.0 \\
\hline
\end{tabular}

be obtained in terms of reproducibility, precedence, and versatility. Various factors and level tables in this study are shown in Table 2, Table 3 and Table 4.

The control factors are injection molding processing conditions resin inlet gate width (Gate width: A), actual temperature control mold temperature (Mold temperature: B), injection cylinder temperature setting resin temperature (Resin temperature: C) , Measurement level of volume required for injection (Measurement level: D), Retention pressure to prevent resin backflow (Retention pressure: E), Screw rotational speed during molding (Screw rotational speed: F), Preheat temperature of bearing bush (Bush tem- perature: G), Virtual factor: $\mathrm{H}$ are assigned to each level.

The noise factors are two types of dies (No.1 Die and No.2 Die) used to process the same product. The signal factors (injection pressure; $4 \mathrm{MPa}, 8 \mathrm{MPa}, 12 \mathrm{MPa}$ ) are set as an input. The reason for setting the signal factor to the injection pressure is that a high injection pressure must be applied to fill the molten resin to the end of the cavity. In the mold, the flow resistance increases as the filling progresses, and injection pressure is applied so that the resin flows by overcoming this resistance to ensure the filling property of the resin.

\subsection{Allocation of "Orthogonal table" and experimental} results Create an "Orthogonal table" which is a statistical tool for making an experimental design, based on the level table.

Table 5 shows the allocation of the orthogonal table and the experimental results. This table shows L18 orthogonal table experimental data (filling density; $\mathrm{kg} / \mathrm{m}^{3}$ ) with control factors (A to $\mathrm{H}$ ) on the inside, and signal factors (M1, M2, M3) and noise factors (N1, N2) on the outside.

In parameter design, mixed orthogonal tables (L12, L18, etc.) are often used for the inner allocation, and only the

Table 5: L18 orthogonal table and experimental data.

\begin{tabular}{ccccccccccccccc}
\hline EXP. & \multicolumn{1}{c}{ Parameter Symbol } & \multicolumn{4}{c}{ M1:4.0 } & \multicolumn{2}{c}{ M2:8.0 } & \multicolumn{2}{c}{ M3:12.0 } \\
Number. & A & B & C & D & E & F & G & H & N1 & N2 & N1 & N2 & N1 & N2 \\
\hline 1 & 0.5 & 165 & 96 & 103 & 35 & 490 & 165 & e1 & 0.755 & 0.771 & 0.771 & 0.775 & 0.785 & 0.789 \\
2 & 0.5 & 165 & 102 & 105 & 45 & 510 & 185 & e2 & 0.760 & 0.773 & 0.775 & 0.776 & 0.786 & 0.790 \\
3 & 0.5 & 165 & 108 & 107 & 55 & 530 & 205 & e3 & 0.761 & 0.771 & 0.779 & 0.824 & 0.805 & 0.814 \\
4 & 0.5 & 175 & 96 & 103 & 45 & 510 & 205 & e3 & 0.763 & 0.770 & 0.769 & 0.773 & 0.779 & 0.785 \\
5 & 0.5 & 175 & 102 & 105 & 55 & 530 & 165 & e1 & 0.781 & 0.798 & 0.799 & 0.806 & 0.811 & 0.820 \\
6 & 0.5 & 175 & 108 & 107 & 35 & 490 & 185 & e2 & 0.780 & 0.795 & 0.820 & 0.825 & 0.829 & 0.834 \\
7 & 0.5 & 185 & 96 & 105 & 35 & 530 & 185 & e3 & 0.779 & 0.791 & 0.796 & 0.806 & 0.812 & 0.826 \\
8 & 0.5 & 185 & 102 & 107 & 45 & 490 & 205 & e1 & 0.769 & 0.781 & 0.798 & 0.808 & 0.825 & 0.835 \\
9 & 0.5 & 185 & 108 & 103 & 55 & 510 & 165 & e2 & 0.781 & 0.799 & 0.823 & 0.830 & 0.829 & 0.849 \\
10 & 0.8 & 165 & 96 & 107 & 55 & 510 & 185 & e1 & 0.786 & 0.802 & 0.855 & 0.865 & 0.864 & 0.875 \\
11 & 0.8 & 165 & 102 & 103 & 35 & 530 & 205 & e2 & 0.785 & 0.811 & 0.869 & 0.871 & 0.872 & 0.879 \\
12 & 0.8 & 165 & 108 & 105 & 45 & 490 & 165 & e3 & 0.782 & 0.795 & 0.811 & 0.816 & 0.822 & 0.832 \\
13 & 0.8 & 175 & 96 & 105 & 55 & 490 & 205 & e2 & 0.763 & 0.781 & 0.785 & 0.792 & 0.795 & 0.810 \\
14 & 0.8 & 175 & 102 & 107 & 35 & 510 & 165 & e3 & 0.761 & 0.779 & 0.786 & 0.789 & 0.791 & 0.812 \\
15 & 0.8 & 175 & 108 & 103 & 45 & 530 & 185 & e1 & 0.745 & 0.769 & 0.774 & 0.775 & 0.780 & 0.789 \\
16 & 0.8 & 185 & 96 & 107 & 45 & 530 & 165 & e2 & 0.765 & 0.782 & 0.785 & 0.791 & 0.796 & 0.823 \\
17 & 0.8 & 185 & 102 & 103 & 55 & 490 & 185 & e3 & 0.781 & 0.798 & 0.806 & 0.811 & 0.821 & 0.815 \\
18 & 0.8 & 185 & 108 & 105 & 35 & 510 & 205 & e1 & 0.785 & 0.821 & 0.825 & 0.829 & 0.835 & 0.845 \\
\hline
\end{tabular}



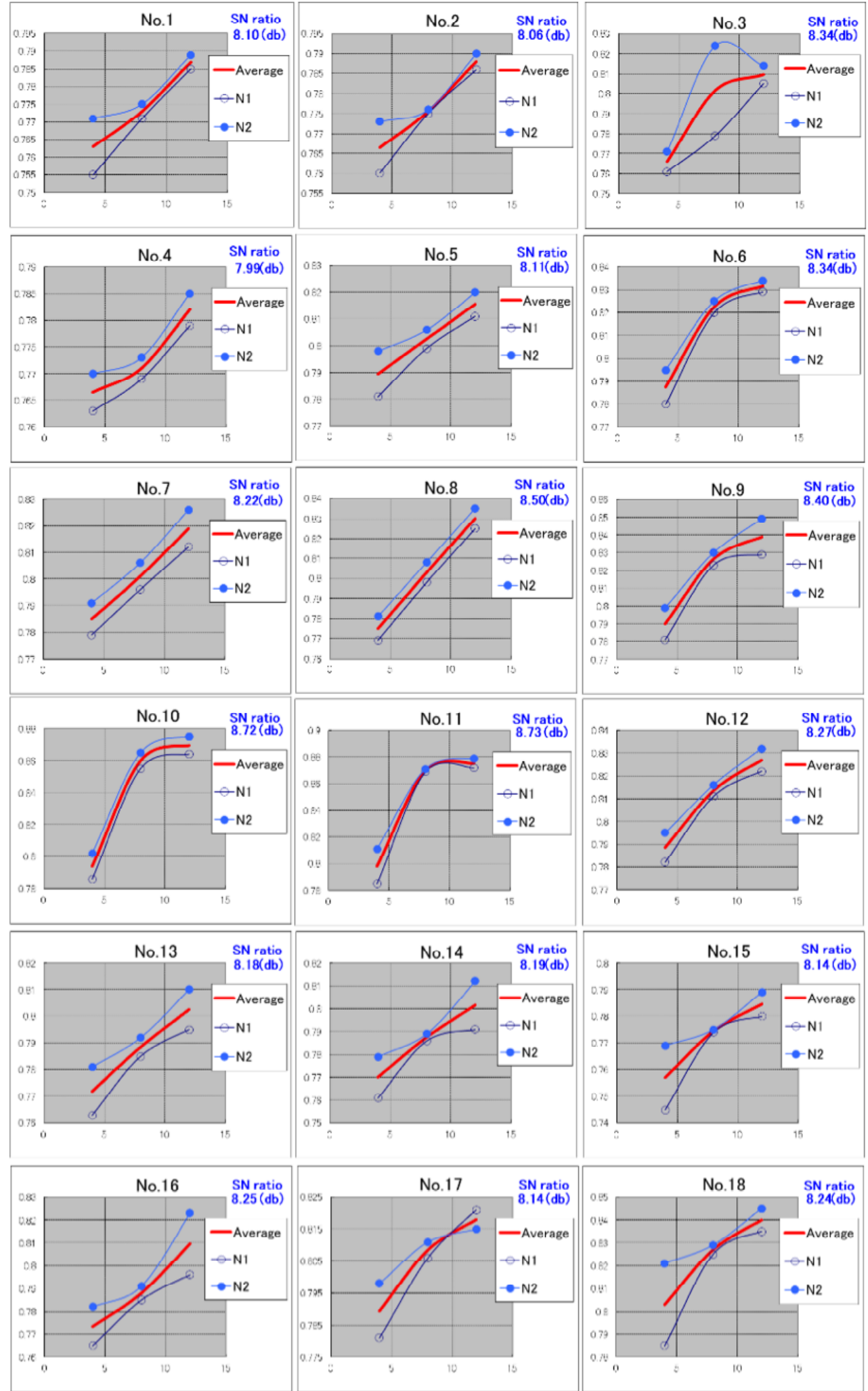

Figure 8: Relationship between injection pressure and filling density.

main effects are allocated. The number of experiments is represented by the experiment number on the left side of the orthogonal table. The number of times of this experiment is 18 , the upper row in the horizontal direction represents the types of control factors, and the values listed below the lev- els represent the levels of the control factors. The advantage of using the orthogonal array is the reduction of the number of experiments, and the number of experiments without the orthogonal array is $2^{1} \times 3^{7}=4,374$ from the establishment of brute force [19]. 
Table 6: SN ratio and Sensitivity.

\begin{tabular}{ccccccccccc}
\hline EXP. & \multicolumn{8}{c}{ Parameter Symbol } & \multicolumn{2}{c}{ Decibel value } \\
\cline { 2 - 7 } Number. & $\mathrm{A}$ & $\mathrm{B}$ & $\mathrm{C}$ & $\mathrm{D}$ & $\mathrm{E}$ & $\mathrm{F}$ & $\mathrm{G}$ & $\mathrm{H}$ & SN ratio & Sensitivity \\
\hline 1 & 0.5 & 165 & 96 & 103 & 35 & 490 & 165 & $\mathrm{e} 1$ & 8.10 & -21.58 \\
2 & 0.5 & 165 & 102 & 105 & 45 & 510 & 185 & $\mathrm{e} 2$ & 8.06 & -21.56 \\
3 & 0.5 & 165 & 108 & 107 & 55 & 530 & 205 & $\mathrm{e} 3$ & 8.34 & -21.34 \\
4 & 0.5 & 175 & 96 & 103 & 45 & 510 & 205 & $\mathrm{e} 3$ & 7.99 & -21.61 \\
5 & 0.5 & 175 & 102 & 105 & 55 & 530 & 165 & $\mathrm{e} 1$ & 8.11 & -21.27 \\
6 & 0.5 & 175 & 108 & 107 & 35 & 490 & 185 & $\mathrm{e} 2$ & 8.34 & -21.11 \\
7 & 0.5 & 185 & 96 & 105 & 35 & 530 & 185 & $\mathrm{e} 3$ & 8.22 & -21.26 \\
8 & 0.5 & 185 & 102 & 107 & 45 & 490 & 205 & $\mathrm{e} 1$ & 8.50 & -21.21 \\
9 & 0.5 & 185 & 108 & 103 & 55 & 510 & 165 & $\mathrm{e} 2$ & 8.40 & -21.05 \\
10 & 0.8 & 165 & 96 & 107 & 55 & 510 & 185 & $\mathrm{e} 1$ & 8.72 & -20.77 \\
11 & 0.8 & 165 & 102 & 103 & 35 & 530 & 205 & $\mathrm{e} 2$ & 8.73 & -20.70 \\
12 & 0.8 & 165 & 108 & 105 & 45 & 490 & 165 & $\mathrm{e} 3$ & 8.27 & -21.17 \\
13 & 0.8 & 175 & 96 & 105 & 55 & 490 & 205 & $\mathrm{e} 2$ & 8.18 & -21.42 \\
14 & 0.8 & 175 & 102 & 107 & 35 & 510 & 165 & $\mathrm{e} 3$ & 8.19 & -21.43 \\
15 & 0.8 & 175 & 108 & 103 & 45 & 530 & 185 & $\mathrm{e} 1$ & 8.15 & -21.60 \\
16 & 0.8 & 185 & 96 & 107 & 45 & 530 & 165 & $\mathrm{e} 2$ & 8.25 & -21.38 \\
17 & 0.8 & 185 & 102 & 103 & 55 & 490 & 185 & $\mathrm{e} 3$ & 8.14 & -21.23 \\
18 & 0.8 & 185 & 108 & 105 & 35 & 510 & 205 & $\mathrm{e} 1$ & 8.24 & -21.02 \\
\hline
\end{tabular}

Table 7: Calculation process.

\begin{tabular}{cccccccccccc}
\hline EXP. & Slope & Divisor & \multicolumn{2}{c}{ Square sum } & \multicolumn{3}{c}{ Antilog } & \multicolumn{2}{c}{ Decibel value } \\
Number. & $\beta$ & $r$ & ST & S $\beta$ & SN $\times \beta$ & Se & SN' & S $\beta /$ SN' & S $\beta / r$ & SN ratio & Sensitivity \\
\hline 1 & 0.083 & 448 & 3.598 & 3.116 & $5.0 \mathrm{E}-05$ & 0.483 & 0.483 & 6.454 & $7.0 \mathrm{E}-03$ & 8.10 & -21.58 \\
2 & 0.084 & 448 & 3.620 & 3.131 & $3.0 \mathrm{E}-05$ & 0.489 & 0.489 & 6.404 & $7.0 \mathrm{E}-03$ & 8.06 & -21.56 \\
3 & 0.086 & 448 & 3.770 & 3.288 & $5.8 \mathrm{E}-04$ & 0.481 & 0.482 & 6.822 & $7.0 \mathrm{E}-03$ & 8.34 & -21.34 \\
4 & 0.083 & 448 & 3.587 & 3.095 & $4.0 \mathrm{E}-05$ & 0.492 & 0.492 & 6.289 & $7.0 \mathrm{E}-03$ & 7.99 & -21.61 \\
5 & 0.086 & 448 & 3.865 & 3.348 & $1.2 \mathrm{E}-04$ & 0.517 & 0.517 & 6.475 & $7.0 \mathrm{E}-03$ & 8.11 & -21.27 \\
6 & 0.088 & 448 & 3.976 & 3.468 & $6.0 \mathrm{E}-05$ & 0.508 & 0.508 & 6.822 & $8.0 \mathrm{E}-03$ & 8.34 & -21.11 \\
7 & 0.087 & 448 & 3.857 & 3.352 & $2.0 \mathrm{E}-04$ & 0.505 & 0.505 & 6.633 & $7.0 \mathrm{E}-03$ & 8.22 & -21.26 \\
8 & 0.087 & 448 & 3.869 & 3.390 & $1.4 \mathrm{E}-04$ & 0.479 & 0.479 & 7.072 & $8.0 \mathrm{E}-03$ & 8.50 & -21.21 \\
9 & 0.089 & 448 & 4.023 & 3.515 & $3.0 \mathrm{E}-04$ & 0.508 & 0.508 & 6.917 & $8.0 \mathrm{E}-03$ & 8.40 & -21.05 \\
10 & 0.092 & 448 & 4.252 & 3.749 & $1.7 \mathrm{E}-04$ & 0.504 & 0.504 & 7.441 & $8.0 \mathrm{E}-03$ & 8.72 & -21.77 \\
11 & 0.092 & 448 & 4.321 & 3.810 & $9.0 \mathrm{E}-05$ & 0.510 & 0.510 & 7.464 & $9.0 \mathrm{E}-03$ & 8.73 & -21.70 \\
12 & 0.087 & 448 & 3.935 & 3.425 & $1.0 \mathrm{E}-04$ & 0.510 & 0.510 & 6.717 & $8.0 \mathrm{E}-03$ & 8.27 & -21.17 \\
13 & 0.085 & 448 & 3.724 & 3.232 & $2.1 \mathrm{E}-04$ & 0.491 & 0.492 & 6.573 & $7.0 \mathrm{E}-03$ & 8.18 & -21.42 \\
14 & 0.085 & 448 & 3.711 & 3.223 & $2.7 \mathrm{E}-04$ & 0.489 & 0.489 & 6.593 & $7.0 \mathrm{E}-03$ & 8.19 & -21.43 \\
15 & 0.083 & 448 & 3.577 & 3.102 & $1.0 \mathrm{E}-04$ & 0.475 & 0.475 & 6.523 & $7.0 \mathrm{E}-03$ & 8.15 & -21.60 \\
16 & 0.085 & 448 & 3.750 & 3.261 & $4.3 \mathrm{E}-04$ & 0.488 & 0.488 & 6.679 & $7.0 \mathrm{E}-03$ & 8.25 & -21.38 \\
17 & 0.087 & 448 & 3.892 & 3.375 & $0.0 \mathrm{E}+00$ & 0.517 & 0.517 & 6.522 & $8.0 \mathrm{E}-03$ & 8.14 & -21.23 \\
18 & 0.089 & 448 & 4.069 & 3.539 & $2.0 \mathrm{E}-04$ & 0.531 & 0.531 & 6.667 & $8.0 \mathrm{E}-03$ & 8.24 & -21.02 \\
\hline
\end{tabular}

Figure 8 shows the input/output relationship graph of injection pressure (horizontal axis: $\mathrm{MPa}$ ) and filling density (vertical axis: $\mathrm{kg} / \mathrm{m}^{3}$ ) for each experiment. From the graph, it can be seen that the relationship between the injection pressure of the input and output and the filling density is a characteristic element that evaluates whether or not there is linearity related to the stabilization of the filling characteristics.

3.6 SN ratio and Sensitivity calculation In parameter design, the $\mathrm{SN}$ ratio of dynamic characteristics is used for functional evaluation, and it is ideal that stable output can be obtained even if there are various errors that affect functional characteristics. To evaluate the functionality, the linearity of the output is examined by changing the input signal. This is the $\mathrm{SN}$ ratio of dynamic characteristics.In this experiment, since the ideal functional state is set for the purpose of stabilizing the fusion energy parameter and the filling density in the injection molding process, "Energetic $\mathrm{S} / \mathrm{N}$ ratio based on zero point proportion" is adopted.

Table 6 shows the SN ratio and sensitivity values from the output data, and Table 7 shows the calculation process of the calculated SN ratio and sensitivity. In functional evalu- 
Table 8: Factor effect table.

\begin{tabular}{|c|c|c|c|c|c|c|}
\hline & \multicolumn{3}{|c|}{ SN ratio Average 8.27} & \multicolumn{3}{|c|}{ Sensitivitys Average -21.26 } \\
\hline \multirow{2}{*}{$\begin{array}{c}\text { Factor } \\
\text { Symbol }\end{array}$} & Level1 & Level2 & Leve3 & Level & Leve2 & Leve3 \\
\hline & \multicolumn{3}{|c|}{ Factor effect } & \multicolumn{3}{|c|}{ Factor effect } \\
\hline \multirow[t]{2}{*}{ A } & 0.5 & 0.8 & & 0.5 & 0.8 & \\
\hline & 8.23 & 8.32 & - & -21.50 & -21.35 & - \\
\hline \multirow[t]{2}{*}{ B } & 165 & 175 & 185 & 165 & 175 & 185 \\
\hline & 8.37 & 8.16 & 8.29 & -21.35 & -21.57 & -21.36 \\
\hline \multirow[t]{2}{*}{$\mathrm{C}$} & 96 & 102 & 108 & 96 & 102 & 108 \\
\hline & 8.24 & 8.29 & 8.29 & -21.50 & -21.40 & -21.38 \\
\hline \multirow[t]{2}{*}{$\mathrm{D}$} & 103 & 105 & 107 & 103 & 105 & 107 \\
\hline & 8.25 & 8.18 & $\underline{8.39}$ & -21.46 & -21.45 & $\underline{-21.37}$ \\
\hline \multirow[t]{2}{*}{$\mathrm{E}$} & 35 & 45 & 55 & 35 & 45 & 55 \\
\hline & 8.30 & 8.20 & $\underline{8.31}$ & -21.35 & -21.59 & -21.34 \\
\hline \multirow[t]{2}{*}{$\mathrm{F}$} & 490 & 510 & 530 & 490 & 510 & 530 \\
\hline & 8.25 & 8.27 & $\underline{8.30}$ & -21.45 & -21.41 & $\underline{-21.42}$ \\
\hline \multirow[t]{2}{*}{ G } & 165 & 185 & 205 & 165 & 185 & 205 \\
\hline & 8.22 & 8.27 & $\underline{8.33}$ & -21.48 & -21.42 & $\underline{-21.38}$ \\
\hline \multirow[t]{2}{*}{$\mathrm{H}$} & e1 & e2 & e3 & e1 & e2 & e3 \\
\hline & 8.30 & 8.33 & 8.19 & -21.41 & -21.37 & -21.51 \\
\hline
\end{tabular}

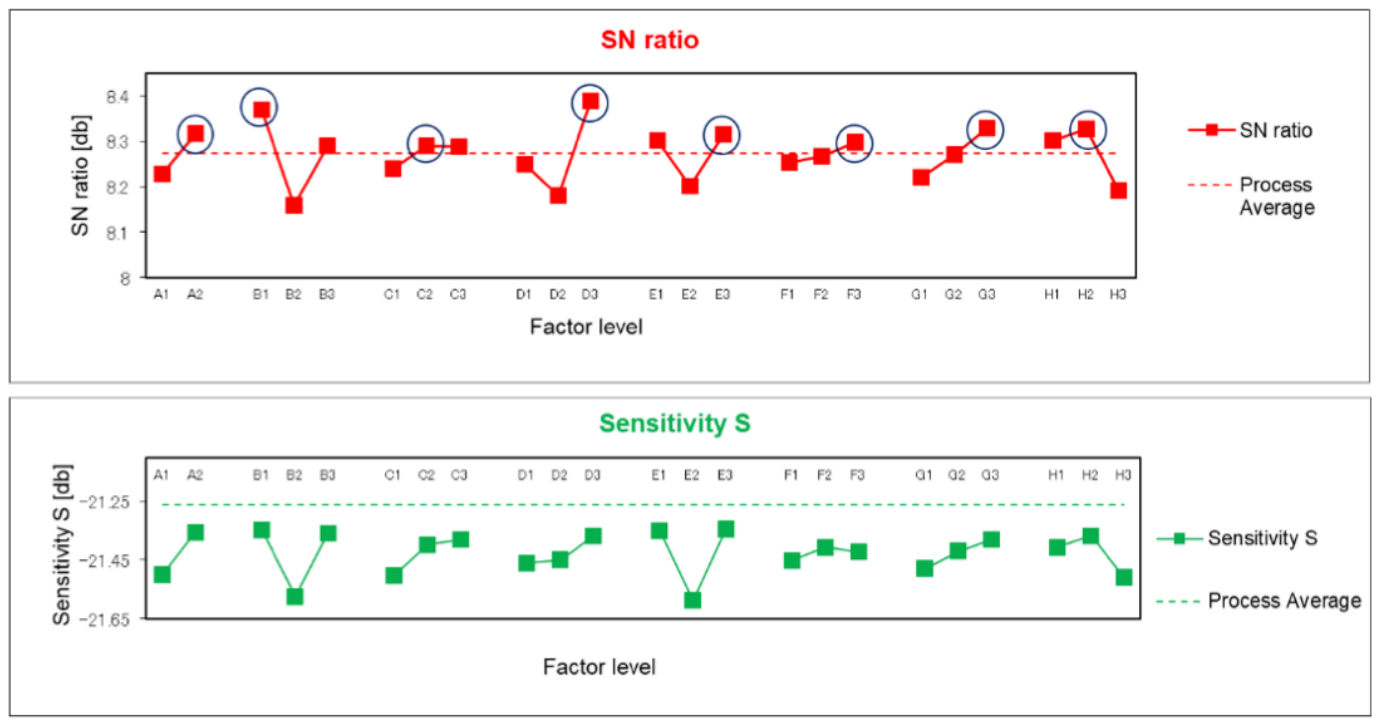

Figure 9: Factor effect diagram of the SN ratio and Sensitivity.

ation, the optimum conditions are obtained by obtaining the SN ratio and sensitivity, and finally determining the presence/absence of effects in the "factorial effect diagram".

3.7 Analysis of factorial effects Figure 9 shows the $\mathrm{SN}$ ratio and sensitivity for each control factor in a factorial effect diagram. The vertical axes in the upper and lower figures represent the SN ratio and sensitivity, respectively, and the horizontal axes represent the factor level. The factor effect table (Table 8) shows the effect of a factor or a combination of factors on the characteristic value, and the diagram that illustrates it is a factor effect diagram.

The significance of this diagram is to extract factors that have a large $\mathrm{SN}$ ratio that spreads vertically and have a small effect on output sensitivity, and it can be judged that their level is highly significant in stabilizing the resin filling characteristics.

In the dynamic characteristic evaluation, it is desirable that the value of the $\mathrm{SN}$ ratio is linearly large, and the optimum conditions are determined based on a comprehensive evaluation comparing the $\mathrm{SN}$ ratio and sensitivity factor effect diagrams. The optimum levels in Fig. 9 are the factors in the circled areas; A2 "Gate width (mm): 0.8", B1 "Mold temperature $\left({ }^{\circ} \mathrm{C}\right): 165$ ", C2 "Resin temperature $\left({ }^{\circ} \mathrm{C}\right)$ : 102 ", D3 "Measurement level (mm): 107", E3 "Retention pressure (MPa): 55", F3 "Screw rotational speed (rpm): 530", G3 "Bush temperature $\left({ }^{\circ} \mathrm{C}\right)$ : 490", H2 "Virtual factor: e2". Table 9 shows the combination of the fusion energy parameter and the control factor level that seems to be optimal for obtaining the stabilization of the filling density in the injection molding process.

3.8 Reliability evaluation of L18 orthogonal table experiment As shown in Table 9, the L18 orthogonal table test results were checked for reliability (additivity) 
Table 9: Optimal results based on estimate and gain.

\begin{tabular}{|c|c|c|c|c|c|c|c|c|c|c|c|c|}
\hline \multirow[b]{2}{*}{ Condition } & \multicolumn{8}{|c|}{ Parameter Symbol } & \multicolumn{2}{|c|}{ Estimate } & \multicolumn{2}{|c|}{ Gain } \\
\hline & A & B & $\mathrm{C}$ & $\mathrm{D}$ & $\mathrm{E}$ & $\mathrm{F}$ & G & $\mathrm{H}$ & $\mathrm{SN}$ ratio & Sensitivity & $\mathrm{SN}$ ratio & Sensitivity \\
\hline Optimal & 0.8 & 165 & 102 & 107 & 55 & 530 & 205 & e2 & 8.72 & -20.85 & 0.47 & 0.49 \\
\hline $\mathrm{BM}$ & 0.5 & 165 & 96 & 103 & 35 & 490 & 165 & e1 & 8.26 & -21.34 & - & - \\
\hline
\end{tabular}

Table 10: Reliability of L18 experiment.

\begin{tabular}{cccc}
\hline $\begin{array}{c}\text { L18 Orthogonal experiment } \\
\text { SN ratio }\end{array}$ & \multicolumn{2}{c}{$\begin{array}{c}\text { By inverse estimation } \\
\text { Reliability check }\end{array}$} \\
\hline Maximum & 8.73 & Obtaained from experiment & 8.10 \\
Minimum & 7.99 & SN ratio of BM estimate & 8.26 \\
Difference & 0.74 & & -0.16 \\
\hline 10\% of difference & $\mathbf{0 . 0 7}$ & $\geq$ Reliable \\
Judgment & & $\mathbf{0 . 1 6}$ \\
\hline
\end{tabular}

based on the result that the estimated value of the optimum condition was higher than the benchmark condition (BM) and the gain was secured.

First, the maximum value and the minimum value of the SN ratio obtained in the L18 orthogonal table experiment are obtained. The judgment method can be judged to be reliable if the difference from the $\mathrm{SN}$ ratio of the $\mathrm{BM}$ condition estimated from the value of $10 \%$ of the difference is within $10 \%$ from the statistical rule of thumb [20].

Table 10 shows the reliability evaluation results. The optimum condition selected by evaluating the variation of the linear relationship between the injection pressure and the filling density and stabilizing the filling density in the injection molding method is a desirable condition, and it can be judged that the L18 orthogonal array experiment is reliable.

3.9 Evaluation of reproducibility by confirmation experiment The purpose of the confirmation experiment is to confirm whether the output is stable even when the time, place, and environment change compared to the orthogonal table experiment. Table 11 shows the evaluation results of the confirmation experiment data. In the confirmation experiment, the $\mathrm{SN}$ ratio of the selected optimum condition and BM condition is obtained, and the same two types as in the orthogonal table experiment are performed again to obtain the $\mathrm{SN}$ ratio. By comparing the difference between the estimated values of the two and the difference (gain) in the confirmation experiment, the reproducibility of the experiment is examined.

Table 12 shows the reproducibility evaluation results in the confirmation experiment. In parameter design, if the reproducibility of gain is within the range of $70 \%$ to $130 \%$, or the gain difference is within $\pm 3 \mathrm{db}$, it can be judged that there is reproducibility. In this experimental result, the reproducibility of the gain was $93 \%$ and the gain difference

Table 11: Confirmation experimental data and SN ratio/Sensitivity calculation results.

\begin{tabular}{cccccccccccccc}
\hline Noise factor & & $\mathrm{N} 1$ & & \multicolumn{3}{c}{$\mathrm{N} 2$} & \multicolumn{4}{c}{ SN ratio } & \multicolumn{4}{c}{ Sensitivity } \\
Signal factor & $\mathrm{M} 1$ & $\mathrm{M} 2$ & $\mathrm{M} 3$ & $\mathrm{M} 1$ & $\mathrm{M} 2$ & $\mathrm{M} 3$ & $r$ & $S_{T}$ & $S_{\beta}$ & $S_{N}$ & $S_{\beta} / S_{N}$ & $\eta_{E}$ & $S_{E}$ \\
\hline BM & 0.748 & 0.758 & 0.756 & 0.735 & 0.740 & 0.738 & 224 & 3.34 & 2.87 & 0.47 & 6.10 & 7.85 & -21.94 \\
Optimal & 0.779 & 0.799 & 0.814 & 0.780 & 0.796 & 0.811 & 224 & 3.81 & 3.31 & 0.50 & 6.62 & 8.21 & -21.32 \\
\hline
\end{tabular}

Table 12: Reproducibility of confirmation experiment.

\begin{tabular}{|c|c|c|c|c|c|c|}
\hline & \multicolumn{2}{|c|}{ SN ratio $[\mathrm{db}]$} & \multirow[b]{2}{*}{ Reproducibility } & \multicolumn{2}{|c|}{ Sensitivity [db] } & \multirow[b]{2}{*}{ Reproducibility } \\
\hline & Estimated & Confirmated & & Estimated & Confirmated & \\
\hline BM condition & 8.26 & 7.85 & $95 \%$ & -21.51 & -22.12 & $103 \%$ \\
\hline Optimal condition & 8.72 & 8.21 & $94 \%$ & -21.00 & -21.48 & $102 \%$ \\
\hline Gain & 0.38 & 0.36 & 93\% & 0.51 & 0.63 & $124 \%$ \\
\hline $\begin{array}{c}\text { Reproducibility } \\
\text { rate } \\
\text { (within } \pm 30 \% \text { ) }\end{array}$ & $70 \% \leqq$ & $\underline{93 \%}$ & $\leqq 130 \%$ & $70 \% \leqq$ & $124 \%$ & $\leqq 130 \%$ \\
\hline $\begin{array}{l}\text { Gain difference } \\
\text { (within } \pm 3 d b \text { ) }\end{array}$ & $\underline{0.03}$ & $\leqq \pm 3 d b$ & & $\underline{-0.12}$ & $\leqq \pm 3 d b$ & \\
\hline Judgment & \multicolumn{6}{|c|}{ Reproducible } \\
\hline Energy loss & $36 \%$ & $1 / 1.55$ & (Times) & Reduction & & \\
\hline Density stability & $20 \%$ & 1.24 & (Times) & Improvement & & \\
\hline
\end{tabular}




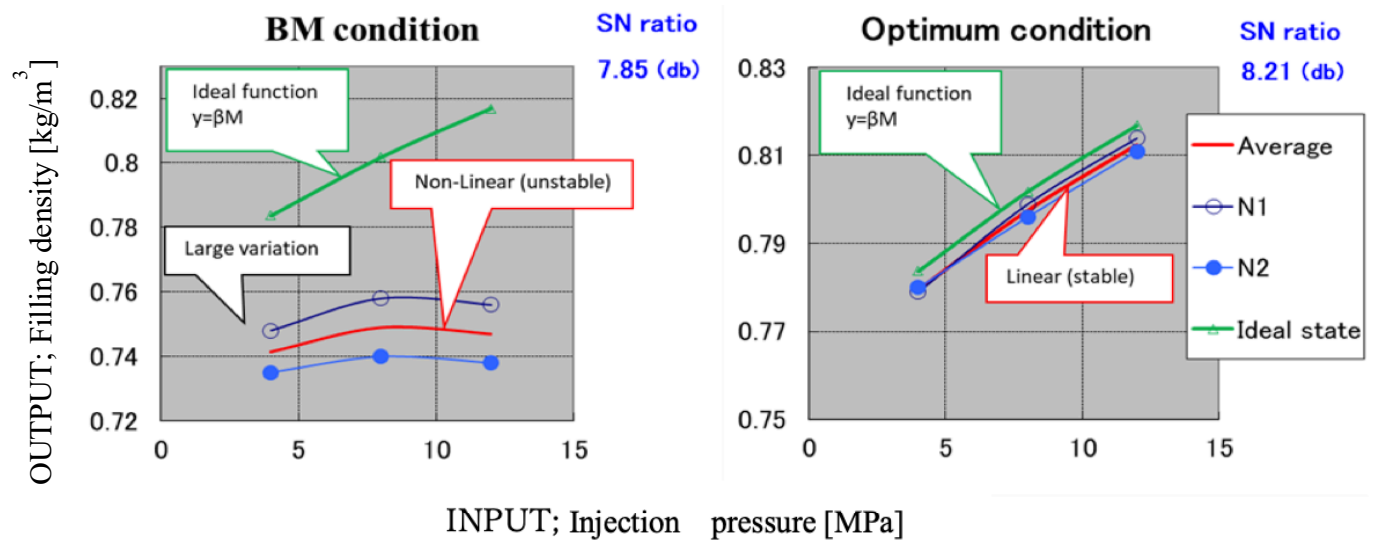

Figure 10: Input/output linearity verification.

Table 13: Process capability index.

\begin{tabular}{c|c}
\multicolumn{2}{c}{ BM } \\
Sample & Data \\
\hline 1 & 0.765 \\
2 & 0.765 \\
3 & 0.764 \\
4 & 0.763 \\
5 & 0.760 \\
6 & 0.759 \\
7 & 0.760 \\
8 & 0.764 \\
9 & 0.754 \\
10 & 0.767 \\
11 & 0.762 \\
12 & 0.760 \\
13 & 0.756 \\
14 & 0.759 \\
15 & 0.765 \\
16 & 0.761 \\
17 & 0.765 \\
18 & 0.762 \\
19 & 0.765 \\
20 & 0.763 \\
\hline Average & 0.762 \\
$\sigma$ & 0.003 \\
$C_{p}$ & $\mathbf{1 . 0 0}$ \\
STW. & 0.020 \\
USL. & 0.770 \\
LSL. & 0.750 \\
\hline &
\end{tabular}

\begin{tabular}{c|c}
\multicolumn{2}{c}{ Optimal } \\
Sample & Data \\
\hline 1 & 0.761 \\
2 & 0.760 \\
3 & 0.760 \\
4 & 0.759 \\
5 & 0.760 \\
6 & 0.763 \\
7 & 0.756 \\
8 & 0.760 \\
9 & 0.758 \\
10 & 0.759 \\
11 & 0.762 \\
12 & 0.759 \\
13 & 0.762 \\
14 & 0.762 \\
15 & 0.761 \\
16 & 0.759 \\
17 & 0.765 \\
18 & 0.762 \\
19 & 0.761 \\
20 & 0.760 \\
\hline Average & 0.760 \\
$\sigma$ & 0.002 \\
$C_{p}$ & $\mathbf{1 . 7 0}$ \\
STW. & 0.020 \\
USL. & 0.770 \\
LSL. & 0.750 \\
\hline &
\end{tabular}

was $0.03 \mathrm{db}$.

Furthermore, the stability improvement rate of the filling density against the BM condition was $20 \%$ and the energy loss was reduced by $36 \%$, indicating that the extracted optimum conditions were properly selected and the set ideal functional state was approached.

Figure 10 is a graph comparing the input and output variations and the linear relationship between the optimum condition and the BM condition in the verification experiment. It shows the change in output (filling density) with respect to input (injection pressure), and it is clear that the optimum condition has a stable linear proportional relationship with less variation than the $\mathrm{BM}$ condition.
3.10 Process capability evaluation by confirmation experiment Table 13 shows the evaluation results of the process capability under the comparison condition (BM) and the optimum condition (Optimum) for the resin filling density (standard $0.760 \pm 0.01 \mathrm{~kg} / \mathrm{m}^{3}$ ) after the injection molding process by the confirmation experiment. The number of samples are $n=20$. "Process capability" is a probability capability that falls within the specifications of the product regarding quality. The "process capability index $\left(C_{p}\right)$ " is used as a measure of the degree of variation in quality characteristics due to process variation, which indicates the stability with respect to the standard range. $C_{p} \geqq 1.00$ is required, and if $C_{p} \geqq 1.33$, it can be judged that the process capability is sufficient.

From the results of Table 13, the process capability is insufficient under the BM condition with $C p=1.00<1.33$, but under the optimum condition, the process capability is sufficient with $C_{p}=1.70>1.33$. The $C_{p}$ data distribution calculated in Table 13 is summarized in the frequency distribution table, and histograms are shown in Fig. 11 and Fig. 12. From the results of the graph, the fluctuation range of the filling density under the optimum condition was reduced compared to the BM condition.

From the results that satisfy the condition of $C_{p} \geqq 1.33$, it can be said that the distribution is close to the normal distribution type (normal type). This indicates that the filling density stability under the selected optimum conditions was improved. $C_{p}$ was calculated by the following formula.

$$
C_{p}=\frac{\mathrm{USL}-\mathrm{LSL}}{6 \sigma}
$$

USL : upper limit standard value

LSL : lower limit standard value

$\sigma:$ Standard deviation

STW : Standard width

$$
\begin{aligned}
\sigma & =\sqrt{\frac{1}{n} \sum_{n=1}^{n}\left(x_{i}-\bar{x}\right)^{2}} \\
n: & \text { total number of data } \\
x_{i}: & \text { individual data } \\
\bar{x}: & \text { average value }
\end{aligned}
$$




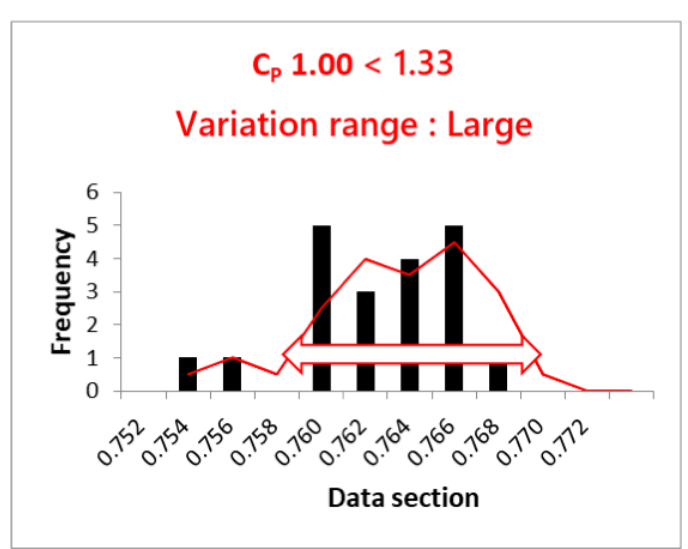

Figure 11: Histogram of BM.

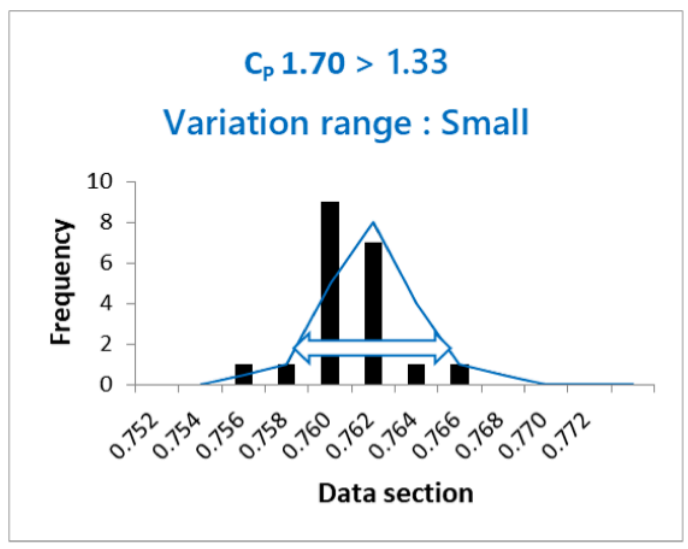

Figure 12: Histogram of Optimal.

\section{Conclusion}

In this study, we focused on the function of controlling the resin filling density in the mold (input/output relationship of melting energy related to resin flow) in optimizing resin strength. From the new definition of resin strength based on material mechanical considerations, we applied a functional evaluation method that has the ideal function of stabilizing the resin filling density.

It was clarified that the uniform resin filling density in the mold, which is a management function, is extremely important for stabilizing the resin strength. As a result of research, we achieved $50 \%$ reduction in in-process defect rate due to abolition of $100 \%$ inspection and defective molding of resin pulleys (cracking/cracking of thin part) by improving process capability of resin filling density which is the current productivity index.

Furthermore, it was verified that the application of the functionality evaluation method, which has the ideal function of stabilizing the resin filling density, brings great knowledge in the optimization of the injection molding process.

As a future research topic, we will focus on the technical basis that the variation of the shape change due to the variation of the shrinkage ratio of the resin in the mold is determined by the response of the mold size and the molded product size, and always has a linear proportional relation- ship. We plan to set a new ideal function for the relationship between the melting energy related to resin flow and the variation of resin shrinkage in the mold, and to further optimize the strength and dimensional accuracy of parts by the functionality evaluation method [22] [24].

\section{Acknowledgment}

We would like to express our deep gratitude to all the people concerned for their great guidance, encouragement, and assistance in the course of carrying out this research.

\section{References}

[1] Taguchi G. and Yano H., "Quality Engineering Application Course "Technology Development of Machinery, Materials and Processing”, Japanese Standards Association, pp.57-89, 2001.

[2] Taguchi G., "Quality Engineering Response Course (5) Quality Engineering Cases", General Edition for Japan, Japan Standards Association, pp.25-100, 1992.

[3] Iwano M., "Development of plastics for automobile parts", Nippon Kogyo Publishing, pp.57-80, 2011.

[4] Taguchi G., "Experimental Design and Quality Engineering", Journal of Quality Engineering, Vol.2, No.1, pp.2-8, 1993.

[5] Taguchi G., "Quality Engineering Course (1) "Quality Engineering at Development and Design Stage", Japan Standards Association, pp.34-68, 1988.

[6] Sugiyama A., "Reexamination of shape retention in injection molding", Proceedings of 10th Quality Engineering Research Conference, pp.18-21, 2002.

[7] Masuda Y., "Optimization of processing conditions in press punching”, Journal of Quality Engineering, Vol.12, No.1, pp.97-104, 2004.

[8] Hatakeyama T., Ishimaru S. and Yasuda M., "Utilization of quality engineering in semiconductor manufacturing process (1)-Method of company-wide development", Journal of Quality Engineering, Vol.12, No.6, pp.66-72, 2004.

[9] Tsuneda S. and Shimizu H., "Study on production process design method of injection molding-From parameter design of plasticizer to analysis by MT system", Journal of Quality Engineering, Vol.19, No.1, pp.44-51, 2011.

[10] Tsuneda S., "Optimization of material drop shape in injection molding machine", Journal of Quality Engineering, Vol.15, No.5, pp.174-180, 2007.

[11] Tsuneda S., "Optimization of injection molding machine conditions for bar flow molds", Journal of Quality Engineering, Vol.16, No.4, pp.53-57, 2008.

[12] Takahashi K., "Optimization of plasticizing equipment for injection molding machines", Journal of Quality Engineering, Vol.13, No.2, pp.53-59, 2005.

[13] Suzuki, M., "Quality engineering not difficult", Nikkan Kogyo Shimbun, pp.34-48, 2016. 
[14] Yano, H., "Introduction to Quality Engineering Calculation Method", Japan Standards Association, pp.74-137. 2002.

[15] Koshimizu S and Suzuki M., "Practical Quality Engineering”, Nikkan Kogyo Shimbun, pp.3-56, 2007.

[16] Hirose K. and Ueda T., "Introduction to Taguchi Method Analysis”, Doyukan, pp.1-24, 2015.

[17] Yano, H., "Introduction to Quality Engineering Calculation Method", Japan Standards Association, pp.74-137, 2002.

[18] Sugiyama A, Hori N. and Yano H., "Transferability and bending of injection molded products Of Injection Molding Machine and Molding Conditions by Surge Test", Journal of quality engineering, Vol.9, No.1, pp.22-30, 2001

[19] Koshimizu S and Suzuki M., "Practice and quality engineering acquired by virtual experiments", Nikkan Kogyo Shimbun, pp.45-68. 2007.

[20] Taguchi G., "Experimental design and quality engineering", Journal of quality engineering, Vol.2, No.1, pp.2-8, 1993.

[21] Tsuruta H., "Energetic S/N ratio", Nikka Giren, pp.17-72, 2016.

[22] Sakurai M. et al., "Evaluation of uniform filling property of injection molded products by MT system", Lecture summary at Nihon University College of Industrial Science, pp.9-12, 2007.

[23] Morita H. and Matsuda J., "Advanced research on ceramics injection molding technology-Optimization of injection conditions for ribbed molded products by quality engineering", Kagoshima Industrial Technology Center Research Report, No.7, pp.29-35, 1993.

[24] Toma E., "Analytical research on resin injection molding process applying "Quality Engineering", The 4th International Conference on Manufacturing Process Technology 2017 (ICMPT-4 2017), August 24-27, 2017.

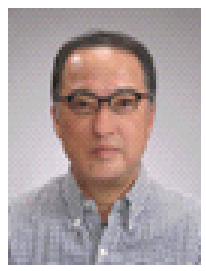

Eiji Toma (Member) He graduated from Kogakuin University Mechanical Engineering Department in 1981. After graduation, he engaged as a production design and quality control engineer at an automobile parts manufacturer. He is presently professor at National Institute of Technology, Tomakomai College. He received Ph.D. in Engineering from Hokkaido University of Science and obtained Professional Engineer (P.E.jp). He was certified as International APEC Engineer (Mechanical) in 2018.

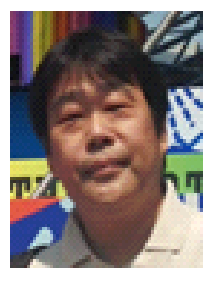

Hiroshi Tanaka (Non-member) $\mathrm{He}$ is a Professor in the Department of Mechanical Engineering at Aichi Institute of Technology, Japan. He received Ph.D. in Engineering from Nagoya University and worked as a process engineer in automobile parts company for 20 years. His research interests include environment friendly manufacturing process and quality engineering.

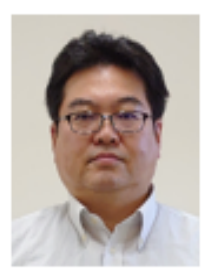

Shinichi Ikeda (Non-member) $\mathrm{He}$ is an Associate Professor in the Department of Engineering for Innovation at National Institute of Technology, Tomakomai College, Japan. He received Ph.D. in Engineering from Muroran Institute of Technology. He is studying in the field of metal cutting for 25 years. 